\title{
Correction to: Cord blood transplantation with a reduced-intensity conditioning regimen using fludarabine and melphalan for adult T-cell leukemia/lymphoma
}

\author{
Nobuaki Nakano ${ }^{1}$ (D) Yoshifusa Takatsuka ${ }^{1} \cdot$ Ayumu Kubota $^{1} \cdot$ Masahito Tokunaga $^{1} \cdot$ Takayoshi Miyazono $^{1}$. \\ Tomohisa Tabuchi ${ }^{1}$. Jun Odawara ${ }^{1}$. Mayumi Tokunaga ${ }^{1} \cdot$ Torahiko Makino $^{1} \cdot$ Shogo Takeuchi ${ }^{1}$ - Yoshikiyo Ito $^{1}$. \\ Atae Utsunomiya ${ }^{1}$
}

Published online: 17 March 2021

(c) Japanese Society of Hematology 2021

Correction to: International Journal of Hematology https://doi.org/10.1007/s12185-021-03102-0

In the original publication of the article, the fourth sentence in the abstract should be "The median age was 62 years (range 44-72), and 21 patients were in complete remission (CR) at the time of CBT".

Publisher's Note Springer Nature remains neutral with regard to jurisdictional claims in published maps and institutional affiliations.

The original article can be found online at https://doi.org/10.1007/ s12185-021-03102-0.

Nobuaki Nakano

nobunobuprince@yahoo.co.jp

1 Department of Hematology, Imamura General Hospital, 11-23 Kamoikeshinmachi, Kagoshima 890-0064, Japan 